\title{
Territorialização e ensino de psicopatologia
}

Conrado Neves Sathler ${ }^{1}$

\section{Resumo}

Este trabalho busca analisar as políticas que sustentam o Ensino de Psicopatologia em cursos de Psicologia por meio da investigação das atividades de Ensino, Pesquisa e Extensão de uma amostragem de 10 currículos lattes de professores de universidades públicas, privadas e confessionais. A hipótese é haver uma territorialização do Ensino constituída como resposta às Políticas Públicas das áreas de interface da Psicopatologia e também aos interesses da clínica privada, da difusão de ênfases teóricas, das Instituições de Ensino, de categorias profissionais e da normatividade da Educação. Este recorte integra a pesquisa A Sala de Aula de Psicopatologia: Discursos e Subjetividades, filia-se à teoria discursiva e compreende o Ensino como dispositivo de formação de subjetividades. Palavras-chave: Discurso; Ensino em Saúde; Formação do Psicólogo; Território.

\section{Territorialization in the teaching of psychopathology}

\begin{abstract}
This work seeks to analyze the policies that support the Teaching of Psychopathology in Psychology courses through the investigation of Teaching, Research and Extension activities from a sample of 10 curriculum lattes of public, private and confessional universities professors. The hypothesis is that there is a territorialization of Education constituted as a response to Public Policies in the interface areas of Psychopathology and also to the interests of the private clinic, the spread of theoretical emphases, the Teaching Institutions, the professional categories and the normativity of Education.This text presents part of the results of the teaching research in the Psychopathology Classroom and understands teaching as a mode of production of subjectivity. Keywords: Discourse; Health Teaching; Teaching of the Psychologist. Territory.
\end{abstract}

\section{Introdução}

Este trabalho se volta à hipótese de que o Ensino de Psicopatologia é dirigido por uma malha de discursos que circulam no território em que a Instituição de Ensino Superior (IES) se insere. O objetivo é empreender uma exposição sistematizada de componentes territoriais que atravessam a construção dos planos de ensino e, quando existentes, dos projetos de extensão e pesquisa docente, considerando a diversidade de possibilidades de entrada no campo psicopatológico.

Compreendemos a Ementa da disciplina de Psicopatologia, em cursos de Psicologia, como a construção de uma parte que se compõe com outros fragmentos disciplinares na formação de

\footnotetext{
${ }^{1}$ Universidade Federal da Grande Dourados, Dourados-MS. E-mail: c.sathler@uol.com.br. 
uma pretensa globalidade orgânica: o Projeto Político Pedagógico (PPP). Logo, a Ementa não pode ser observada como um dado isolado dos demais componentes do PPP como a Matriz Curricular e o perfil do egresso, pois é ligada tanto a essas construções internas da IES quanto aos interesses políticos da rede de poderes que o circundam e lhe conferem legitimidade. Fazem parte dessa rede: normativas do Ministério da Educação, política de Saúde vigente, associações universitárias e mecanismos de financiamento para estudantes, ou seja, as estruturas econômicas e sociais mais amplas que envolvem a escolarização. A Ementa é a síntese, o resultado final dessas construções (SATHLER; MASCIA, 2020).

Da mesma forma, o docente de uma disciplina não é um sujeito autônomo, desvinculado, é, antes de qualquer outra coisa, o resultado de uma seleção organizacional, seja por cumprir critérios estrategicamente elencados em um edital público de concorrência aberta ou por atender pontualmente os critérios de um escrutínio privado (SATHLER; MASCIA, 2019).

Uma IES se instala em um território e deve se integrar às suas malhas atendendo suas demandas, isso significa que deve produzir subjetividades implicadas na manutenção dos poderes e na distribuição de bens desse território. A instituição formativa, como qualquer outra, se mantém somente ao constituir-se como elemento indispensável à produção do sujeito que nela se fabrica. Para isso, divide responsabilidades e atribuições com outras instituições concretas, validando-as e sendo validada por elas, vinculando-se a uma malha na qual a população se distribui.

A Psicopatologia se inscreve na população e no território como uma política, mais justamente, como um agenciamento biopolítico produtor de subjetividades e de lugares sociais, atribuindo bioidentidades e dispondo a população em jogos de linguagem que permitem a relação com as instituições concretas, entre os pares e de cada um consigo mesmo, nomeando e delimitando a autoexpressão, provocando a diferenciação e a sensação de pertença a uma categoria reconhecida (WEINMANN, 2006; MARTINS, 2008; ROSE, 2001). Essas categorias Psicopatológicas são regidas por uma lógica normalizadora, uma regra social instaurada pela estatística estruturante da Ciência Política, da Governamentalidade ou dos olhos do poder governamental sobre a população.

O conceito foucaultiano que, compreendido como ferramenta analítica, identifica essa lógica e mostra sua organização é a Ontologia Histórica e há importantes desdobramentos desse 
conceito em textos de Hacking e Rose. Hacking (2001-2002; 2004-2005) aponta como as classificações das identidades e expressões humanas, tidas como classificações naturais, são políticas com poder de constituir e modificar o comportamento dos sujeitos classificados, modificando-os. A essa modificação de comportamento Hacking (2013) chama de Efeito de Laçada, e Rose (2001a, 2001b) constrói a história dos modelos de referência a si, um dobramento que associa signos a objetos, derivados da linguagem Psi, postos e naturalizados em signos que exteriorizam as subjetividades. Assim, essa dobra não delimita ou enclausura um eu, mas tornao efeito de uma função ou operação de delineamento.

Partimos da pressuposição de que esse mecanismo de produção de subjetividades - a ontologia histórica - se dê em resposta às Políticas Públicas de Saúde, Saúde Mental, Segurança, Educação e Assistência Social, entre outras, que se caracterizam como intervenções coletivas organizadas pelo Estado, mas também como arquitetura plasmada em atenção às práticas de mercado dispostas como mecanismos individualizantes como as práticas clínicas de psicoterapia e de medicalização da população (SIBILIA; JORGE, 2016). Por fim, as descrições ontológicas confeccionam suporte também aos próprios sujeitos classificados que, por meio de lobbys ou de redes sociais, buscam imprimir nas descrições e classificações suas próprias representações discursivas. Vale ressaltar que o DSM 5, quinta edição do manual diagnóstico editado pela Associação Americana de Psiquiatria com grande circulação nos serviços de Saúde Mental, estabeleceu, por meio de um website, uma linha direta com usuários e grupos de interesse para debater as classificações, conforme exposto em seu subitem da introdução Revisão Pública e Profissional (APA, 2014, p.8).

Interessa-nos perceber como, atravessado pelas gestões públicas coletivas ou nas práticas individuais e individualizantes do mercado privado, o Ensino de Psicopatologia se constitui em territorialidades para fazer valer a lógica da economia máxima e redução de custos, da ampliação dos mercados clínicos das psicoterapias, da manutenção dos ambulatórios públicos e comunidades terapêuticas, da medicalização e, também, da busca de acomodação disciplinar e de maior produtividade dos sujeitos. Na mesma direção, buscamos examinar como o Ensino reage aos movimentos de reconhecimento de instituições de internamento e consequente segregação social de usuários de drogas, por exemplo.

Documentos oficiais e públicos referentes ao Ensino de Psicopatologia e artigos recentes 
sobre a formação em Psicologia foram acessados pela rede mundial de computadores, além disso foram selecionados projetos desenvolvidos em IES e outras atividades de professores da disciplina para empreendermos uma análise minimamente empírica. Empregamos as informações sobre as atividades acadêmicas de Ensino, Pesquisa e Extensão como analisadores e o mecanismo da territorialização como campo investigativo. E, para tornar mais claro o método empregado, definimos os conceitos de território e territorialização enquanto dinâmica nas relações de poder e também como dispositivos de produção de subjetividades.

\section{Território, territorializações e modos de atuação em ensino em saúde}

Compreendemos Território como o lugar em que o governo se exerce (FOUCAULT, 2008a). Isso significa que a população, bens, relações, instituições, regras de deslocamento e ocupação do espaço estão inseridos nesse conceito. Além disso, governar um determinado território implica exercer domínio político e administrativo sobre sua população e o valor do território compõe o valor do sujeito que o ocupa.

Para além do controle dos objetos e do comportamento da população, há a gestão dos desejos, das tendências e das formas dos gestos projetados de cada indivíduo. Para Foucault (2003), atualmente vigora uma Ciência Política cuja construção passou por refinamentos, antes governar era dispor da população como instrumento para manutenção do patrimônio. Torna-se, num primeiro passo, uma gestão do espaço e dos bens pertencentes a quem o habita. $\mathrm{Na}$ sequência, a Segurança, a Saúde e o Trabalho começam a ser esquadrinhados estatisticamente, mais precisamente estadisticamente. Dessa forma, realizados os controles estatísticos, os cálculos possibilitam, por meio do conhecimento dos desejos e valores, que o cidadão enuncie: este governo que aí está sabe exatamente o que eu preciso.

Há múltiplas territorializações sobrepostas constituindo um mesmo território. As territorializações inscrevem as formas políticas de administração da população. Para delinear esse campo de governo, hoje, podemos falar de domínios fiscais, de registros de bens, de hábitos de consumo, de regimes de trabalho e de saúde que organizam o trânsito, as relações e os saberes como dispositivos a serviço dos governos pela via das produções e controle de subjetividades, ou ainda, pelas ações dirigidas pelos poderes transversais sobre o território. 
A Biopolítica exerce, nesse contexto, a função de dispositivo governamental de territorialização (CASTRO, 2009). Esse dispositivo atravessa os corpos, individual e coletivamente, organizando e conduzindo sua saúde, condição imunológica, longevidade etc.; estabelece uma lógica demográfica com o controle da fertilidade, da morbidade e da longevidade, consequentemente, do emprego dos corpos nos postos de trabalho; passa também pelos controles epidêmicos e endêmicos e pelas prescrições de dietas e medicamentos. Assim, em cada espaço, a Biopolítica regula a adequação ao clima, a disponibilidade de água e de alimentos e os movimentos da população como coletividade. Todos esses artifícios perfazem produções de modos de existir, de parâmetros para comportamentos de trabalhadores em formação, ativos e aposentados, com a finalidade de sustentar economicamente o Estado.

A Psicopatologia, como conjunto de signos que liga sujeitos a comportamentos desejáveis ou indesejáveis, é um dos componentes da Biopolítica. Logo, uma faceta da territorialidade se faz pela via das classificações psicopatológicas. Ao criar regras divisórias de comportamentos, a Psicopatologia estabelece critérios diagnósticos que especificam o normal e o patológico, embute um crivo com marcas ideológicas sobre cada um e permite encaminhamentos para cada tipo elencado em seus breviários, mais ou menos excludente ou aceito. A psicopatologia é um dos agentes institucionais do Estado, é uma chave de leitura do olho do poder do Estado. Esses olhos, desde a criação do panóptico de Benthan até a construção de rotas viárias, passando pelas práticas da Arquitetura e do Urbanismo, estão a serviço dessa territorialização (FOUCAULT, 2010).

O poder não é representado corretamente quando observamos unicamente seu modo de ação como força restritiva. O sujeito "deve" ou "pode" ou, ainda, o sujeito "não deve" ou "não pode" são padrões coercitivos e limitantes, portanto, pouco frutíferos. O poder é produtivo na medida em que estabelece condições para existências, resistências e ações múltiplas cujos campos de ação podem ser, de maneira mais restrita ou mais ampla, deslocados, transgredidos e reformulados. O poder é exercido porque há liberdade.

A Ciência Polícia propõe que o Estado funcione como uma cidade, a capital é a praça e as estradas são as ruas. A cidade é vigiada como grande panóptico, o vigilante é um camarada e cada sujeito é também um agente particular de controle. Esse modelo é um regime no qual o Estado se exerce: a malha do poder (FOUCAULT, 2012). 
Assim como a Assistência Social e a Polícia Comunitária, a Assistência à Saúde no país carrega a marca da territorialidade. Entre seus princípios estão Universalidade e Integralidade e entre as diretrizes estão Descentralização, Regionalização e Hierarquização (MATTA, 2007), conceitos territoriais. O Ensino em Saúde, em qualquer de seus núcleos de saber, é um exercício e uma inserção de agentes territorializados.

Esse funcionamento territorial é, também, atravessado pelo modelo econômico neoliberal (FRAZÃO; MINAKAWA, 2018; VIANA; SILVA, 2018). Com isso, não negamos as propriedades da Universalidade, Integralidade e Equidade do Sistema Único de Saúde, apenas reafirmamos a preocupação constante em sua administração voltada para a resolutividade e para o financiamento dos territórios. Essa ação deveria ser centrada nas ações preventivas e na reabilitação do sujeito da Saúde, gerando diminuição de gastos. Mas, com os ajustes neoliberais, há uma espécie de desterritorialização da economia pública, com reterritorialização pelos serviços terceirizados, empreendedorismos individuais e coletivos de especialistas.

Como elemento transversal, o modelo neoliberal dirige também a Educação. Do mesmo modo, as IES privadas devem ser lucrativas, as IES confessionais devem ser autossustentáveis e financiar parte de suas missões institucionais e as IES públicas são reembolsadas por produtividade, ou seja, pelo número de egressos. Os Programas de Pós-Graduação têm parâmetro na produtividade acadêmica e promovem, da seleção de ingressantes ao credenciamento de novos professores, seleções baseadas em ranqueamento de pontuação que valoriza o número de produtos levados ao mercado. Essas competições produzem o homo oeconomicus, fazendo convergir interesses centrados na quantidade de mercadorias (FOUCAULT, 2008b).

Esse é o atravessamento que nos dispõe em um Ensino para além do público e do privado, pois, tanto nos equipamentos públicos quanto nos gabinetes particulares, estamos todos na regra do mercado competitivo. Assim, podemos observar condutas profissionais resistentes com intervenções dirigidas aos valores de uma ética de cuidados que se contrapõem à Psiquiatria de Mercado, à Análise Instrumental e à Psicoterapia Adaptativa, no entanto, mesmo resistentes, as práticas de cuidados são afetadas pelo pensamento neoliberal. 


\section{Práticas docentes e territorialidades}

Em nosso primeiro procedimento metodológico, faremos a discriminação das IES dos professores de nossa amostragem em públicas, privadas e confessionais. Esse critério nos propicia analisar os regimes administrativos que ordenam algumas territorializações do Ensino. A seleção da amostra se deu pela acessibilidade dos dados (GIL, 1999), em nosso caso, o acesso virtual se deu seguindo critérios de representatividade na distribuição geográfica dos cursos. As regiões centro-oeste, sudeste e sul foram as escolhidas. Os professores, cujos currículos lattes foram analisados, trabalham regularmente com a disciplina de Psicopatologia. Mantivemos o anonimato dos professores e da IES.

Nesta amostragem de 10 professores, quatro atuam em IES privadas do interior das regiões sudeste e sul, duas pertencentes a grandes redes de ensino e duas a IES com único campus, sendo uma universidade e um centro universitário. Três professores atuam em IES confessionais, uma localizada numa capital do sudeste e as outras duas em cidades do interior no sul e no centro-oeste. Três professores em IES públicas, uma está localizada em nova unidade de ensino deslocada da sede, outra em sede nova, ambas no sudeste, e a terceira em uma IES estadual no sul.

Dentro do recorte de regime administrativo há outro atravessamento territorial que logo se destaca: a localização das IES se dá em capital de estado ou em cidade do interior com destacada história universitária. As IES públicas são mais frequentes em capitais ou em cidades expressivas política e economicamente em sua região. As IES privadas se localizam em capitais ou em cidades estrategicamente localizadas para atender, com maior frequência em cursos noturnos, estudantes trabalhadore(a)s. Diferentemente das IES públicas caracterizadas pela organização acadêmica de Universidade, nas quais a pesquisa é regimental, as IES privadas ou as confessionais podem se organizar como Centros Universitários e Faculdades isoladas. Nessas IES, a pesquisa não é uma obrigatoriedade para autorização de funcionamento. As IES confessionais não obedecem aos mesmos critérios territoriais, mas os de suas próprias congregações religiosas.

Essa sobreposição de territorialidades, status da cidade e categoria administrativa da IES, constitui parte das condições de Ensino dos cursos de Psicologia, pois há diferenças na 
disponibilidade de equipamentos públicos e de eventuais equipamentos substitutivos ligados à própria IES e, consequentemente, diferenças nas ações de Políticas Públicas ao alcance da comunidade e da academia, o que altera a percepção e o tipo de engajamento das comunidades, inclusive dos profissionais dos campos de estágio. Observações sobre as diferenças do funcionamento da Atenção em Saúde Mental em cidades de pequeno e médio, por exemplo, podem ser vistas em Luzio e L`Abbate (2009).

Podemos observar que os estatutos administrativos das IES se refletem no tempo de contratação dos docentes analisados. O tempo médio de permanência, em nossa amostragem, é de 6,5 anos nas IES privadas, 17,6 nas confessionais e 19 nas públicas. Os três docentes das IES públicas são contratados em regime de Dedicação Exclusiva. Nas confessionais, um é contratado em regime integral (40h) e dois em regime parcial (20h). Nas IES privadas, um por 40h, um não declarou e os dois restantes em $20 \mathrm{~h}$ e $12 \mathrm{~h}$.

A titulação docente é outra regularidade observada. Nas IES privadas todos têm a titulação de mestre, nas IES públicas todos são doutores e nas IES confessionais um é doutor, um é mestre e outro é especialista. Apenas dois professores entre os docentes não são psicólogos, são psiquiatras e estão alocados em IES confessionais.

O território elege subjetividades e os professores, neste sentido, são agentes políticos a serviço da malha do poder. O professor é sustentado pelos discursos que faz circular na academia. Cabe lembrar aqui Foucault (1996) que aponta alguns controles discursivos externos: a sociedade do discurso, a disciplina e a doutrina. Os professores recebem um mandato, recortam um fragmento dos saberes e cumprem regras que promovem a percepção de um discurso verdadeiro. As atividades de ensino resultam, então, da comunidade na qual se insere a IES, dos interesses que a atravessam, das condições de contratação e, finalmente, das filiações filosófica, religiosa, profissional, política e doutrinária do professor.

Como dissemos, o poder governamental se exerce no território. O professor é um agente no território e a IES é um componente do território que obedece às regras da Ciência Política. Nossa análise separa esses componentes, mas compreendemos que todos participam de forma interligada, interatuante e interdependente do processo de territorialização e, igualmente, estão submetidos aos controles legais do Estado. Mas, enfatizamos, territorialidade é movimento, o controle é sempre um devir e a formação territorial não tem direção linear e estável. 
As atividades de Ensino estão inscritas em um PPP, logo, partes de uma construção coletiva e uma disciplina é sustentada por outros saberes disciplinares. Como organização territorial, buscamos observar as atividades de Ensino, Pesquisa e Extensão de um mesmo docente. Isso não significa que outros professores não trabalhem com os mesmos compromissos discursivos dos docentes de Psicopatologia nem que haja ausência de conflitos e disputas discursivas nessas atividades.

As regularidades encontradas nas IES privadas foram as tipicamente ligadas à clínica, de forma que a Psicopatologia se liga aos estágios clínicos e, em especial, à Psicanálise. Há, nos estágios, uma exceção, um deles se desenvolve na perspectiva da Saúde Coletiva. Há participações docentes em cursos de Pós-Graduação lato sensu. E, como condição de trabalho docente, há um extremo em nossa amostra, talvez não represente uma excepcionalidade, um docente dedica 30 horas semanais à sala de aula e ministra mais de 10 disciplinas.

Observamos nas IES confessionais alguma territorialização biomédica, não apenas pela formação em Psiquiatria de seus docentes, mas pela concomitância de trabalho das disciplinas de Psicopatologia e Psicofarmacologia. Aparecem, ainda, componentes curriculares como Clínica Psicanalítica, Estudos da Personalidade e Ética.

Nas IES públicas há outro padrão de territorialização. Os docentes estão envolvidos em projetos temáticos nos quais o Ensino é uma parte das atividades organizadas que abarcam também Pesquisa e Extensão. Dois professores atuam em Graduação e em Pós-Graduação simultaneamente. Há, nas disciplinas desses dois níveis de formação, afinidade temática definida pela linha de pesquisa na qual o docente inscreve sua carreira. Um dos professores atua no campo da Psicologia Social e, desta maneira, disciplinas como Análise Institucional, Linguagem e Psicologia Social são suas ofertas regulares. Um professor centrado nas Intervenções Clínicas trabalha disciplinas na Graduação e na Pós-Graduação, orienta trabalhos científicos e se envolve com a divulgação científica desta área. O terceiro atua em Políticas Públicas, não é professor permanente em Programa de Pós-Graduação e é engajado em uma política que procura atravessar nosso Sistema de Saúde.

As atuações dos professores das IES públicas permitem observar regularidades expressas pela presença transversal de temáticas em clínicas tradicionais ou clínicas ampliadas da saúde, cultura, novas formas de adoecimento, desafios sociais e intervenções alinhadas às Políticas 
Públicas. Em especial, a temática das drogas foi identificada em mais de um docente, com presença em projetos que vão desde o desenvolvimento de escalas diagnósticas até a participação em Órgãos de Controle Social. O financiamento público de pesquisas oferecido pela Secretaria Nacional de Políticas Sobre Drogas estava ligado a essa temática, isso significa que, nesses casos, o financiamento público e aberto possivelmente interferiu nessas territorializações.

Outra característica regular dos professores das IES públicas é a participação em colegiados de Cursos, Comissões, Conselhos Universitários e Coordenação de Graduações e PósGraduações. Essa vivência oportuniza ações na construção da própria territorialidade, de forma direta com a construção de sua carreira e, também, dos cursos e das IES onde são servidores efetivos. Ressaltamos que a estabilidade de emprego permite a existência de conflitos e diferenças políticas, filosóficas e pedagógicas nas relações institucionais.

Nas IES confessionais há também participação dos professores em colegiados e Núcleos Docentes Estruturantes. A contratação em regime integral ou parcial insere o professor em espaços complementares à sala de aula. Assim, a circulação do professor e os interesses voltados mais à formação de subjetividades ligadas aos objetos da missão institucional, à filosofia e à política são contemplados pela via de grupos de estudos. Essas condições permitem a participação em Grupos de Pesquisa internos ou externos às IES. Observamos, nos regimes parciais de contratação, professores com atividades profissionais não acadêmicas como psicólogos clínicos ou funcionários públicos atuando diretamente nos campos de Saúde Mental, cotidianamente.

Os professores das IES privadas investigados apresentam jornada excessiva, em média 13h diárias, considerando trabalhos docentes e não docentes. Um dos professores não informa sua jornada, mas o número de suas atividades indica ser longa. As atividades administrativas contêm coordenações de cursos e de estágios sem qualquer menção às comissões, colegiados ou outras instâncias decisórias nas IES.

Mesmo com jornadas extensas, foram declaradas duas participações em Projetos de Pesquisa e um deles com produção de artigos em revistas reconhecidas nas avaliações acadêmicas. Esse último mantém concentradas suas atividades em sala de aula e publicações nos campos da Psicanálise, Saúde Mental e Psicopatologia. 
Os outros professores têm suas atividades pulverizadas com temáticas díspares concomitantes. Saúde, violência, dependência virtual, trânsito, alienação parental, dependência de drogas e intervenções clínicas em abordagens teóricas distintas compõem cenários mais ou menos frequentes. Suas orientações de Trabalhos de Conclusão de Curso denunciam essa pulverização, nas quais, aparentemente, os estudantes escolhem um tema aleatório e um orientador. Um discurso institucional inclui a todos nessas instituições: atender bem o cliente. Nesse âmbito, atender bem significa aceitar a opção do(a) estudante e orientá-lo(a) na construção de um texto disciplinar com formatação científica. O docente, nessas circunstâncias, orienta inúmeros trabalhos com temáticas distintas simultaneamente, sem um grupo de pesquisas ou de estudos que permitam avanços científicos ou técnicos significativos nos campos de conhecimento.

Há variações que apontam uma regularidade de vinculação territorial do trabalho docente no contraturno do emprego principal. Assim, por exemplo, o profissional que trabalha em um Tribunal de Justiça ou em um Centro de Referência em Assistência Social contribui para a formação profissional com suas experiências. Essa territorialização tende a delimitar a atuação docente a atividades mais próximas a sua rotina de trabalho não acadêmico.

A sobreposição da atividade acadêmica e profissional no mercado de trabalho não acadêmico traz para a formação parte expressiva de uma experiência profissional. Esse é um mecanismo territorial que cumpre a função de legitimação da qualidade de Ensino. O professor ocupa um lugar profissional, quando no serviço público, para o qual foi concursado, isso o valoriza na academia e estar na academia aumenta a credibilidade do profissional em seu campo de trabalho. Com alguma regularidade, esse professor atua em sala de aula e em supervisão de estágio na mesma área e leva seus estagiários para o seu próprio lugar de exercício. O Ensino torna-se uma extensão do trabalho profissional e o trabalho profissional um complemento à formação (SATHLER; MASCIA, 2019).

As sobreposições das territorialidades são patentes nesse caso, pois a clientela das IES privadas, majoritariamente, é da mesma comunidade que acolhe a IES ou próximas a ela. O professor é parte da comunidade, é também agente político da instituição na qual exerce seu trabalho não acadêmico que se torna parte de suas atribuições acadêmicas. Com essa interseção, o território é compartilhado por todos os elementos do Ensino. 
Quando o professor trabalha exclusivamente para IES privadas, seus limites de atuação são mais porosos e, consequentemente, as áreas com as quais trabalha são mais diversas. Nesse caso, a territorialidade do Ensino se dá na própria IES, uma vez que ela se torna o lugar de formação e o exemplo vivo dos modos de sobrevivência no mercado neoliberal. Considerando ainda que as IES privadas, invariavelmente, fazem suas contratações em regime horista e sem continuidade garantida de vinculação, há ameaça de desemprego que, supostamente, força o professor a atender a instituição e agradar seus alunos como clientes comerciais e essa territorialização torna-se um modelo de uma educação voltada à sobrevivência no mercado.

\section{Tensões temporais no ensino e disputas territoriais}

A disciplina de Psicopatologia se insere nos PPP como base conceitual para outas disciplinas como Avaliação Psicológica, Psicologia Clínica e Psicologia do Trabalho. O objetivo dos PPP é fabricar subjetividades politicamente consonantes com os objetivos das IES formadoras. Pode-se argumentar, a partir dessa premissa, que os objetivos podem ser econômicos, religiosos, político-ideológicos etc., porém, focamos nas consequências sociais dessas escolhas e, por conseguinte, na territorialização do Ensino e das subjetividades forjadas pelas IES.

Encontramos, no levantamento de textos científicos sobre Formação em Psicologia, artigos preocupados com os rumos assumidos pelas IES. Esses artigos foram produzidos após a publicação das Diretrizes Curriculares Nacionais (DCN) de 2004, atualizada em 2011 para normatizar as licenciaturas como curso complementar, última alteração normativa sobre a Formação em Psicologia (BRASIL, 2011).

As tensões mais observadas na leitura desses artigos, em nossa análise, podem ser lidas sob a perspectiva territorial em alguns eixos. Os artigos apontam os acertos nas DCN que dirigem as formações para as Políticas Territoriais de acordo como a Constituição Federal de 1988, a Constituição Cidadã. Nela, o cidadão brasileiro constitui-se como sujeito de direitos e as DCN se voltam à formação dessa subjetividade. Saúde, Educação, Assistência Social, Segurança, Transporte e Direitos Individuais são valores postos como compromissos do Estado e a Psicologia, como Ciência e Profissão, se desloca para assistir essa formação. No entanto, os artigos denunciam o conservadorismo na Educação e afirmam que há desafios para atender, por 
meio de intervenções profissionais do conjunto da sociedade, ao projeto de nação delineado pela própria Constituição.

A formação profissional anterior às novas DCN se pautava em um currículo mínimo que pendia para a territorialidade privada. A clínica, a escola e a indústria eram focos de formação e os procedimentos técnicos mais trabalhados eram fundados em avaliação, classificação e adaptação. Assim, atender novas demandas de formação de comunidades pautadas na inclusão social, na participação democrática e na defesa de direitos das populações discriminadas, excluídas e invisibilizadas tornam-se desafios e reterritorializações da cidadania (BERNARDES, 2012; AMENDOLA; 2014; RECHTMAN; BOCK, 2019).

A reterritorialização impõe desafios e os autores pesquisados os descrevem como necessidade de intensificar as formações humana, ética e política para subsidiar novos modos de subjetivação (LIMA; SOUZA, 2014) e também para apoiar o imperativo da apropriação das políticas sociais de Assistência Social, Saúde, Proteção à Criança e aos Adolescentes etc. (SEIXAS et al., 2016).

Há um enfrentamento mais pontual nesse processo territorial. A abertura de novos cursos no interior do país pode empobrecer a formação diante da riqueza de possibilidades de atuação (LISBOA; BARBOSA, 2009; MACEDO et al.,2017), especialmente quando reproduzem um PPP padronizado sem adaptações à realidade local ou, ao contrário, quando utilizam as potencialidades locais sem apropriarem-se de pesquisas e intercâmbios que possam provocar novas perspectivas territoriais.

O tripé da formação universitária se constitui de Ensino, Pesquisa e Extensão. No entanto, muitas IES buscam a excelência em Ensino sem atuar em Pesquisa e Extensão. A Pesquisa realizada de forma sistemática e contínua, com projetos reconhecidos avaliados por pares e por grupos credenciados é realizada, majoritariamente, por IES públicas (SATHLER; MASCIA, 2019). A Pesquisa e a Extensão, de forma associada, indicam uma concepção de construção territorializada de saberes e de experiências como afirmam Huning e Gomes (2019, p.109)

Desse modo, o conhecimento que propomos não é simplesmente algo do âmbito teórico ou proveniente de uma ascese intelectual. Ele é atravessado pela experiência dos nossos corpos situados e pelos encontros e desencontros que nos constituíram ao longo de nossas caminhadas em territórios acadêmicos e urbanos e propõe, explicitamente, o desmonte de um modo de fazer pesquisa 
por muito tempo considerado o único legítimo e que se sustentou na universalização de uma ficção chamada subjetividade ocidental.

A pesquisa significa também a prática de uma busca fundamentada e sistemática de produção de saberes, experiências e subjetividades que intervenham junto à coletividade. Logo, o exercício da Pesquisa Científica é em si mesmo uma prática política.

A Psicopatologia é uma parte desse dispositivo formativo e é necessário implicá-la, também, com os desafios postos pela nova territorialização, como já apontamos em Sathler e Mascia (2020).

\section{Considerações finais}

A territorialidade é um atravessamento político-administrativo que dispõe a população em espaços que indicam as possibilidades de existência e, um pouco mais que isso, o valor do sujeito em uma relação próxima com o valor do espaço ocupado.

A Psicopatologia pode ser tomada como um dispositivo identitário e produtor de subjetividades mais ou menos adequadas, adaptadas e desejadas. Essa atribuição a faz desempenhar um papel de destaque nos mecanismos governamentais.

As políticas de Saúde, Segurança, Educação, Assistência Social e de Trabalho, permeadas pelas diretrizes econômicas dos governos das populações, atravessam não somente a Psicopatologia como saber, mas engajam seu Ensino nos projetos mais investidos, nas atividades reconhecidas pela sociedade segundo suas possibilidades econômicas de acesso e de sobrevivência das IES no mercado de formação profissional. Desta forma, o Ensino reproduz a lógica da redução de custos e máxima economia nas políticas internas das IES (formas de contratação, utilização de recursos virtuais etc.) e em suas territorializações pedagógicas (incentivo ao empreendedorismo individual, estímulo à ampliação dos mercados clínicos individuais e coletivos particulares etc.).

O corpo docente das IES reflete a institucionalização de seus regimes administrativos (públicos, privados, confessionais...) e de suas organizações acadêmicas (Universidade, Centro Universitário ou Faculdade). Isso significa que a autonomia para a construção de um PPP pode ser total, quando construído pelo próprio colegiado do curso, parcial, quando sua construção é 
supervisionada por uma matriz administrativa, ou inexistente, quando o PPP é padronizado e os docentes de uma unidade não podem modificá-lo. Essa territorialidade constrói também um docente mais ou menos autônomo.

Por fim, a Psicopatologia, tomada como saber básico para o desenvolvimento de práticas profissionais, precisa responder ao desafio temporal no qual toda a formação em Psicologia está posta, o que significa, em termos territoriais, avançar dos modelos biomédicos para os modelos de formação de subjetividades, das práticas de clínica privada para as práticas centradas nas Políticas Públicas e na compreensão dos processos de Ensino, Pesquisa e Extensão como projetos políticos e não como práticas de transmissão de saberes instituídos como verdades estáveis, permanentes e universais.

\section{Referências}

AMENDOLA, M. F. Formação em psicologia, demandas sociais contemporâneas e ética: uma perspectiva. Psicol. cienc. prof., Brasília, v.34, n.4, p.971-983, dez. 2014. Disponível em: http://www.scielo.br/scielo.php?script=sci_arttext\&pid=S141498932014000400971\&lng=pt\&nrm=iso. Acesso em: 14 abr. 2020. DOI: https://doi.org/10.1590/1982-370001762013.

APA - AMERICAN PSYCHIATRY ASSOCIATION. Manual diagnóstico e estatístico de transtornos mentais: DSM-5. Trad. Maria Inês C. Nascimento. Porto Alegre: Artmed, 2014.

BERNARDES, J. S. A formação em psicologia após 50 anos do primeiro currículo nacional da psicologia: alguns desafios atuais. Psicol. cienc. prof., Brasília, v.32, p.216-231, 2012. Disponível em: http://www.scielo.br/scielo.php?script=sci_arttext\&pid=S141498932012000500016\&lng=pt\&nrm=iso. Acesso em: 14 abr. 2020. DOI: https://doi.org/10.1590/S1414-98932012000500016.

BRASIL. Resolução CNE/CES n ${ }^{\circ}$, de 15 de março de 2011. Diretrizes Curriculares Nacionais para os cursos de graduação em Psicologia, 2011. Disponível em: http://portal.mec.gov.br/index.php?option=com_docman\&view=download\&alias=7692rces005-11-pdf\&ltemid=30192. Acesso em: 16 abr. 2020.

CASTRO, E. Vocabulário de Foucault. Belo Horizonte: Autêntica, 2009.

FOUCAULT, M. A governamentalidade. In: MOTTA, M. B (org.). Ditos e escritos, vol. IV: estratégia poder-saber. Trad. Vera Lúcia A. Ribeiro. 2. ed. Rio de Janeiro: Forense Universitária, 2003. p.281-305. 
FOUCAULT, M. Segurança, território e população: curso no Collège de France 1977-1978. Trad. Eduardo Brandão. São Paulo: Martins Fontes, 2008a.

FOUCAULT, Michel. A ordem do discurso: aula inaugural no Collège de France em 02 de dezembro de 1970. 6. ed. Rio de Janeiro: Loyola, 1996.

FOUCAULT, M. Nascimento da biopolítica: curso no Collège de France 1978-1979. Trad. Eduardo Brandão. São Paulo: Martins Fontes, 2008b.

FOUCAULT, M. O olho do poder. In: MOTTA, M. B (org.). Ditos e escritos, vol. VI: repensar a política. Trad Ana Lúcia P. Pessoa. Rio de Janeiro: Forense Universitária, 2010. p.107-125.

FOUCAULT, M. As malhas do poder. In: MOTTA, M. B (org.). Ditos e escritos, vol. VIII: segurança, penalidade e prisão. Trad. Vera Lúcia A. Ribeiro. Rio de Janeiro: Forense Universitária, 2012. p.168-188.

FRAZÃO, P.; MINAKAWA, M. M. Medicalização, desmedicalização, políticas públicas e democracia sob o capitalismo. Trab. educ. saúde, Rio de Janeiro, v.16, n.2, p.407-430, ago. 2018. Disponível em: http://www.scielo.br/scielo.php?script=sci_arttext\&pid=S198177462018000200407\&lng=pt\&nrm=iso. Acesso em: 07 abr. 2020. DOI: https://doi.org/10.1590/1981-7746-sol00123.

GIL, A. C. Métodos e técnicas de pesquisa social. 5. ed. São Paulo: Atlas, 1999.

HACKING, I. Philosophie et histoire des concepts scientifiques. Résumé des cours: façonner les gens - 2001/2002. Disponível em: https://www.college-de-france.fr/media/ianhacking/UPL7997567846150782232_Hacking2001_2002.pdf. Acesso em: 29 maio 2018.

HACKING, I. Philosophie et histoire des concepts scientifiques. Résumé des cours: figure de I'autism - 2004/2005. Disponível em: https://www.college-de-france.fr/media/ianhacking/UPL7997567846150782232_Hacking2001_2002.pdf. Acesso em: 29 maio 2018.

HACKING, I. Construindo tipos: o caso de abusos contra crianças. Trad. Mariza Corrêa. Cad. Pagu, Campinas, n.40, p.7-66, jun.2013. Disponível em:

http://www.scielo.br/scielo.php?script=sci_arttext\&pid=S0104-

$83332013000100001 \&$ Ing=pt\&nrm=iso. Acesso em: 03 abr. 2020. DOI: https://doi.org/10.1590/S0104-83332013000100001.

HUNING, S. M.; GOMES, C. A. R. A pesquisa-experiência na psicologia: corpos, afetos e experiências em territórios urbanos. Psicol. cienc. prof., Brasília, v.39, n.2 [esp.], p.100-111, 2019. Disponível em: http://www.scielo.br/scielo.php?script=sci_arttext\&pid=S141498932019000600300\&lng=pt\&nrm=iso. Acesso em: 18 abr. 2020. DOI: https://doi.org/10.1590/1982-3703003225540. 
LIMA, V. C.; SOUZA, R. T. Formação humana e competências: o debate nas diretrizes curriculares de psicologia. Psicol. Soc., Belo Horizonte, v.26, n.3, p.792-802, dez. 2014. Disponível em: http://www.scielo.br/scielo.php?script=sci_arttext\&pid=S010271822014000300027\&lng=pt\&nrm=iso. Acesso em: 14 abr. 2020. DOI: https://doi.org/10.1590/S0102-71822014000300027.

LISBOA, F. S.; BARBOSA, A. J. G. Formação em psicologia no Brasil: um perfil dos cursos de graduação. Psicol. cienc. prof., Brasília, v.29, n.4, p.718-737, 2009. Disponível em:

http://www.scielo.br/scielo.php?script=sci_arttext\&pid=S141498932009000400006\&lng=pt\&nrm=iso. Acesso em: 14 abr. 2020. DOI: https://doi.org/10.1590/S1414-98932009000400006.

LUZIO, C. A.; L'ABBATE, S. A atenção em saúde mental em municípios de pequeno e médio portes: ressonâncias da reforma psiquiátrica. Ciênc. saúde coletiva, Rio de Janeiro, v.14, n.1, p.105-116, fev.2009. Disponível em: http://www.scielo.br/scielo.php?script=sci_arttext\&pid=S1413$81232009000100016 \&$ Ing=pt\&nrm=iso. Acesso em: 05 abr. 2020. DOI: https://doi.org/10.1590/S1413-81232009000100016.

MACEDO, J. P. et al. Transnacionalização do ensino superior: impactos nos processos formativos em psicologia no Brasil. Psicol. cienc. prof., Brasília, v.37, n.4, p.852-868, dez. 2017. Disponível em: http://www.scielo.br/scielo.php?script=sci_arttext\&pid=S141498932017000400852\&lng=pt\&nrm=iso. Acesso em: 14 abr. 2020. DOI: https://doi.org/10.1590/1982-3703004272016.

MARTINS, A. L. B. Biopsiquiatria e bioidentidade: política da subjetividade contemporânea. Psicol. Soc., Florianópolis, v.20, n.3, p.331-339, dez. 2008. Disponível em: http://www.scielo.br/scielo.php?script=sci_arttext\&pid=S010271822008000300003\&lng=pt\&nrm=iso. Acesso em: 30 maio 2018. DOI: https://doi.org/10.1590/S0102-71822008000300003.

MATTA, G. C. Princípios e diretrizes do sistema único de saúde. In: MATTA, G. C.; PONTES, A. L. M. (orgs.). Políticas de saúde: organização e operacionalização do sistema único de saúde. Rio de Janeiro: EPSJV/FIOCRUZ, 2007, p.61-80.

RECHTMAN, R.; BOCK, A. M. B. Formação do psicólogo para a realidade brasileira: identificando recursos para atuação profissional. Psic.: Teor. e Pesq., Brasília, v.35, 2019. Disponível em: http://www.scielo.br/scielo.php?script=sci_arttext\&pid=S010237722019000100600\&lng=pt\&nrm=iso. Acesso em: 14 abr. 2020. DOI: https://doi.org/10.1590/0102.3772e3551.

ROSE, N. Como se deve fazer a história do EU? Trad. Tomaz T. da Silva. Educação e Realidade, Porto Alegre, v.26, n.1, p.33-57, jun./jul. 2001. 
SATHLER, C. N.; MASCIA, M. A. A. Lugar docente de psicopatologia em cursos de psicologia: biopolítica, governamentalidade e subjetividade. Currículo sem Fronteiras, v.19, n.3, p.13391357, set./dez. 2019. Disponível em:

https://www.curriculosemfronteiras.org/vol19iss3articles/sathler-mascia.pdf. Acesso em: 30 mai. 2020. DOI: http://dx.doi.org/10.35786/1645-1384.v19.n3.31.

SATHLER, C. N.; MASCIA, M. A. A. Uma análise discursiva de ementas de psicopatologia em cursos de psicologia. ETD - Educação Temática Digital, Campinas, v.22, n.1, p.127-144, 2020. Disponível em: https://periodicos.sbu.unicamp.br/ojs/index.php/etd/article/view/8651957. Acesso em: 30 mai. 2020. DOI: 10.20396/etd.v22i1.8651957.

SEIXAS, P. S. et al. As políticas sociais nos fundamentos dos projetos pedagógicos dos cursos de Psicologia. Psicol. Esc. Educ., Maringá, v.20, n.3, p.437-446, dez. 2016. Disponível em: http://www.scielo.br/scielo.php?script=sci_arttext\&pid=S141385572016000300437\&lng=pt\&nrm=iso. Acesso em: 14 abr. 2020. DOI: https://doi.org/10.1590/2175-3539201502031005.

SIBILIA, P.; JORGE, M. F. O que é ser saudável? entre publicidades modernas e contemporâneas. Galáxia, São Paulo, n.33, p.32-48, dez. 2016. Disponível em: http://www.scielo.br/scielo.php?script=sci_arttext\&pid=S198225532016000300032\&lng=pt\&nrm=iso>. Acesso em: 01 abr. 2020. DOI: https://doi.org/10.1590/1982-25542016225865.

VIANA, A. L. D.; SILVA, H. P. Meritocracia neoliberal e capitalismo financeiro: implicações para a proteção social e a saúde. Ciênc. saúde coletiva, Rio de Janeiro, v.23, n.7, p.2107-2118, jul. 2018. Disponível em: http://www.scielo.br/scielo.php?script=sci_arttext\&pid=S141381232018000702107\&lng=pt\&nrm=iso. Acessos em 07 abr. 2020. DOI: https://doi.org/10.1590/1413-81232018237.07582018.

WEINMANN, A. O. Dispositivo: um solo para a subjetivação. Psicol. Soc., Porto Alegre, v.18, n.3, p.16-22, dez. 2006. Disponível em:

http://www.scielo.br/scielo.php?script=sci_arttext\&pid=S0102-

71822006000300003\&lng=pt\&nrm=iso. Acesso em: 30 maio 2018. DOI: https://doi.org/10.1590/S0102-71822006000300003.

Recebido em abril 2020.

Aprovado em fevereiro 2021. 